\title{
Principals' Perceptions about Alternate Route Programs in Rural Areas
}

\author{
Devon Brenner \\ Mississippi State University \\ Anastasia Elder \\ Mississippi State University \\ Sarah Wimbish \\ Tishomingo County School District \\ Sara Walker \\ Mississippi State University
}

\begin{abstract}
Alternate route programs are increasingly serving schools in rural areas that may struggle to recruit new teachers. In this study, ten principals of middle schools from rural areas of Mississippi were interviewed regarding their perceptions of alternate route programs' recruitment, selection, preparation, mentorship, support, and retention practices. Qualitative analysis of semi-structured interviews suggests that principals of rural schools had limited experience with alternatively certified teachers and, overall, their views were generally positive. They believed that these programs would help meet the high need for teachers in the state, and alternate route candidates may provide benefits to middle school students due to their greater content knowledge, experience, and maturity. However, they also held concerns regarding the absence of student teaching, alternatively certified teachers' readiness for the classroom, and the amount and quality of support and mentoring in the first year of teaching.
\end{abstract}

Keywords: alternate route, principals' beliefs, rural, middle school

Rural schools often struggle to recruit new teachers and retain the teachers they hire. Challenges for recruiting new teachers have been attributed to a variety of factors, including lower salaries and inadequacy of local resources, lack of adequate housing and isolation, and prospective teachers' assumptions about students and communities in rural areas (Johnson, Showalter, Klein, \& Lester, 2014; Pennefather, 2008; Schafft \& Jackson, 2010). Recruiting can be especially challenging for schools located in communities serving high concentrations of families living in poverty (Monk, 2007). In Mississippi, where this study was located, one-third of schools are identified as critical shortage districts, with high percentages of classrooms staffed by individuals teaching in areas for which they are not licensed or staffed by long-term subs rather than licensed teachers (Mississippi Department of Education, 2015).

Policies to address rural teacher shortages often focus on incentives-loan forgiveness, hiring incentives, housing support, which can help to encourage new teachers to consider applying for and accepting jobs in rural communities. Another strategy getting increasing attention is to identify local residents with an interest in teaching to create a pipeline of new teachers with roots in the community and understanding of local cultures, teachers who might be more likely to not only begin teaching but stay in the classroom longer than the 3-5 years common for many new rural teachers (Feistritzer \& Haar, 2008; Wang, 2014).

Alternate route programs, programs that provide a route to teacher licensure for individuals who have earned Bachelor's degrees in other fields, can serve schools and districts in rural areas that may have a difficult time recruiting new teachers. Alternate route teacher preparation programs, especially those offered in a distance format, can help districts "grow their own" teachers for schools in rural areas where prospective teachers may have limited access to traditional teacher education programs.

Alternate route teacher education programs are distinguished from traditional teacher education programs in that they provide a path to licensure for individuals who did not participate in a four-year undergraduate teacher education program. The National Center for Education Information estimates that approximately 250,000 teachers have been certified through alternate route programs of one sort 
or another. They have become quite common across the United States and exist in nearly every state, though there is great variation across states in the need for and reliance on alternative pathways to prepare teachers (Feistritzer \& Haar, 2008; Grossman \& Loeb, 2008). In some states, such as Mississippi, more than half of new teachers earn their credentials through alternate route programs (Mississippi Department of Education, Office of Educator Licensure, personal communication, 2013). In other states these licensure programs are much less common.

Traditional teacher education programs at fouryear institutions generally consist of a combination of content area and education coursework, field experiences, and a culminating multi-week student teaching internship. Alternate route programs, on the other hand, take a variety of forms and designs. They may be university based or operated by non-profit or even for-profit organizations. Alternate route programs are organized in a variety of ways, including short induction programs with a great deal of "on-the-job" training, graduate programs with multiple courses that mimic traditional undergraduate programs, or may consist of a combination of preservice and in-service coursework and professional development. Alternate route programs may consist of university-based coursework, be embedded in schools and classrooms, through online delivery, or any combination of these (Zeichner \& Hutchinson, 2008).

Because alternate route certification programs vary in their intent, design, and delivery, it is difficult to draw conclusions about the impact of alternative programs on teacher effectiveness (Ing \& Loeb, 2008). However, several studies examining student outcomes show that students can achieve at least as well as in classrooms led by alternatively certified teachers as those led by traditionally prepared teachers (e.g. Boyd, Goldhaber, Lankford, \& Wyckoff, 2007; Constantine, Player, Silva, Hallgren, Grider, \& Deke, 2009; Goldhaber \& Brewer, 2000).

In 2012, faculty in the elementary education program area at our institution launched an online alternate route licensure program. The Master of Arts in Teaching-Middle Level Education (MAT-M) degree program was designed to prepare new teachers for elementary and middle school classrooms in rural communities. We hoped that the MAT-M at our university, funded in part by a US Department of Education Transition to Teaching grant, would be a strong, evidence-based program that would provide teacher licensure for individuals already in possession of a Bachelor's degree. Ideally, these individuals also have roots in the communities they will serve and a commitment to teaching in rural communities in Mississippi.

The MAT-M program requires participants to enter with an undergraduate degree from an accredited institution and offers an opportunity to become a teacher in grades 4-8. Following state requirements, participants complete six hours of online coursework and earn initial licensure, after which they are eligible to be hired as teacher of record and complete a year-long internship while they continue taking online courses. The program was developed around standards for middle level educators from the Association of Middle Level Education (AMLE, 2012). The degree is offered entirely online in order to serve rural schools and communities across the state.

We intended the MAT-M at our university to provide a strong alternative to programs already in our state such for-profit and community collegebased programs. Our state is also served by large numbers of temporary teachers who fulfill service commitments through programs such as Teach for America. As we launched the MAT-Middle degree program against the backdrop of these programs, we were worried about rural administrators' knowledge of alternate route programs and their perceptions of their relative quality and effectiveness.

One factor that can have an impact on the success of an alternate route program is the perception of principals about alternative certification. Principals who are skeptical of the value of alternative programs might be less likely to hire alternatively certified teachers. Principals' perceptions of alternative licensure programs might also lead them to provide different levels of support and mentoring for alternatively certified teachers.

We wanted to know whether principals would hesitate to hire graduates of an alternate route program or have concerns about the effectiveness of alternatively certified new teachers. In particular, we were interested in administrators' perceptions of alternate route programs' recruitment and selection practices, their views of alternatively certified teachers' preparedness for the classroom, their assumptions about levels of support and concerns about retention that might impact decisions to hire alternatively certified teachers.

\section{Administrators' Perceptions of Alternatively Certified Teachers}

Several researchers have focused on administrators' perceptions of the quality of alternate route teachers and their preparation for the classroom. Hall (2008) interviewed 12 alternatively certified teachers and their supervising principals 
from across the state of Arkansas. She found that alternatively certified teachers were perceived as equal to traditional route teachers in regards to professionalism and classroom management. Principals reported that alternate route teachers seemed to be more willing to accept criticism and brought diversity from their training and education to the classroom. Finn (2009) conducted similar research regarding principals' perceptions of alternate route teachers and reviewing components of "highly qualified" as set by No Child Left Behind, 2001. Surveys of 82 principals from the Dallas Independent School District suggested that principals' experiences with alternatively certified teachers led them to believe that both groups of teachers were equivalently prepared in terms of professionalism, resource development, developing and implementing lesson plans, differentiating instruction, and communication, but that principals were divided in opinion about alternatively certified teachers' ability to implement classroom management.

Hall (2008) and Finn (2009) both showed that principals viewed alternatively certified teachers as equivalent to their traditionally certified counterparts. However, other research suggests that administrators may have qualms about alternatively certified teachers. For example, Wagmeister (2006) interviewed nine administrators who supervised first year teachers in California. The administrators described the importance of field experiences, particularly student teaching, and believed that traditionally prepared teachers were more competent with pedagogy, possess greater special education procedural knowledge, ability to work with parents, manage time, and collaborate with colleagues, in part because of their pre-service field experiences. The principals also reported that alternatively trained teachers tended to be more easily overwhelmed, exhibit higher levels of stress, and had difficulty individualizing instruction. Similarly, Johnson (2010) interviewed administrators in a southeastern city and found that administrators responsible for hiring teachers preferred to hire traditionally prepared teachers because of assumptions that teachers with alternative certification might possess greater content knowledge but were not as strong in areas of pedagogy and management.

Currently, research is limited regarding administrators' perceptions regarding alternate route teacher candidates, especially in rural areas. Few studies have been conducted and those that do examine administrators' perceptions are inconsistent. With this study, we aimed to understand rural principals' perspectives on alternate route teacher licensure so that we could inform our own program design and implementation and so that we could contribute to understandings of alternative certification programs in rural settings.

\section{Methods}

Principals in nearby rural districts were invited to share their perceptions of alternate route licensure programs. Ten principals agreed to participate in semi-structured interviews about their perceptions of alternate route teacher preparation, selection, mentoring, support, recruitment, and retention. All but one of the principals worked at rural schools with high percentages of students receiving free and reduced lunch that serve a predominantly white, rural student population.

Principals were interviewed in order to learn more about their perceptions of alternatively certified teachers. The interview questions were organized around the Qualitative Indicators developed by the National Association of Alternative Certification (NAAC, 2012). The NAAC has identified six primary functions of alternate route programs that impact the quality of the program and outcomes for participants, including: (1) recruitment, (2) selection, (3) preparation, (4) mentoring, (5) support, and (6) retention. The semi-structured interview opened with a general question asking about their view of alternate route education in the state. Then, the interviewer briefly defined each of the six functions and asked principals about their knowledge of and beliefs about how well alternate route programs in the state fulfill these functions. In these ways, we were able to understand principals' perceptions about the individuals who earn alternate route licensure, the quality of alternate route certification programs, and their sense of the level of support new alternate route teachers might need during the first years of teaching.

Digital recordings of the interviews were transcribed for the purpose of analysis and coding, and principals were identified with letters (A-J). First, the transcripts were reviewed multiple times in order to document similarities and to develop a coding system for the participants' responses, including coding responses question by question and reviewing responses of each participant to construct a series of issues and concerns principals had in each of the six inquired areas. Second, transcripts and coding of questions were further reviewed to identify trends that cut across the questions - these were organized into major themes principals believed about alternate route and frame the results presented next.

\section{Results and Discussion}

Principals told us that they generally had a positive impression of alternate route programs in the 
state. They believed that alternate route programs are efficient for addressing teacher shortages. For example, Principal G told us, "I believe it's good to get more teachers in the state of Mississippi ... there's a need for teachers." Principal I stated, "I know that alternate route is very necessary in the state of Mississippi to get enough teachers, quality people, in the classroom or needs areas in the state." The principals we spoke with believed that alternative certification programs serve a need in the state and can provide strong teachers for classrooms, but they also raised some concerns. Here we will examine themes that emerged as principals spoke about their perceptions of the individuals who seek alternate route licensure, their concerns about alternatively certified teachers readiness for the classroom, beliefs about levels of support and mentoring needed during the first years of teaching, and their assumptions about recruiting practices, especially scholarships and incentives, and the impact of incentive programs on teacher retention.

\section{Perceptions of the Individuals who Seek Alternative Certification}

Principals' perceptions of the people who choose to become alternatively certified teachers and of the ways that alternate route programs recruit potential teachers and select candidates for licensure might impact their beliefs about alternatively certified teachers. Most of the principals reported that they knew very little about how alternate route teachers are recruited or identified and did not have strong opinions regarding the caliber of teachers recruited to alternate route programs in the state or the admission requirements of alternate route programs. As Principal A told us, the pool of alternatively certified teachers likely includes individuals who "decided that it was either their calling" or "they couldn't find job in their chosen field, so they say, 'I'll go teach.",

In general, principals also believed that alternate route teachers brought previous employment or life experiences and background knowledge that could make them stronger in the classroom. Principal B said, "I think that it's certainly something that could bring a lot to the area of education when you've got someone who's not just fully ingrained in education to come out of industry or some other field."

Principal H stated, "I'd like to see more knowledgeable, educated teachers - people with a business background, people with a science background that didn't go through the traditional college of education." These principals hoped that alternate route teachers would bring deeper knowledge of the disciplines they had studied and/or experience, which is often touted as a benefit of alternate route degree programs. Some stated that this would be especially beneficial for secondary educators who teach single topics (i.e., Algebra, Biology, Chemistry, etc.). Because of their experience in an undergraduate major or in employment, alternatively certified teachers might be more knowledgeable about their subject matter than many traditionally certified teachers.

In spite of a general consensus about the content knowledge and experience of alternatively certified teachers, a few principals had misconceptions about lower standards for alternate route programs. For example, one principal did not know about academic standards for admission to alternate route licensure programs. The state of Mississippi requires minimum GPAs and that alternatively certified teachers pass the state's content area licensure exam prior to beginning an alternate route preparation program. However, principal $\mathrm{H}$ told us:

\begin{abstract}
We need to be weeding out ... the people that ... maybe they didn't have very good grades in college . . . I definitely think it needs to be some way that we not open the gate and let everyone come in, it needs to be filtered. . . I don't know how close they're looking at that kind of stuff.
\end{abstract}

This principal's perceptions of alternate route programs lack of a "filter" is likely to also impact hiring decisions and interactions with potential teachers for his district.

Two other principals raised concerns about alternatively certified teachers' ability to interact with students and families. For example, principal A asked, "Do they have the social interaction skills that ... would be needed to be a successful teacher? That's the biggest problem I see right now." Also, principal A wished that there was a way to screen alternate route teachers' abilities to interact, or to "go through and analyze what kind of people skills they do have." Principal J told us some people “don't need to be teachers because simply they don't have the patience, they can't empathize, they can't bridge the gap, they can't build that kind of relationship, and I just think those are vital elements." These principals raised concerns that alternate route teachers might not possess the interaction or people skills they would need to succeed.

\section{Perceptions about New Alternate Route Teachers' Level of Readiness to Teach}

Overall, the principals felt that the alternate route teachers they had themselves hired or had interacted with in classrooms were well prepared. Their experiences with alternate route teachers were generally positive. As principal D put it, "I can't 
really tell the difference." In fact, many spoke of the strengths of the alternate route teachers in their schools. Said principal J, "I taught with a teacher here who got her engineering degree ... She went and got certified alternate route, and she was probably one of the best math teachers I've ever seen. She did an outstanding job." Principal F highlighted the potential of alternate route bringing some diverse perspectives to the classroom:

I believe that an alternate route student could possibly bring a different vision based upon maybe their prior experiences that they might have encountered from a different profession ... or past work experiences. From my dealings with alternate route education, those students tend to be a little more mature age-wise ... that's an asset that alternate route education can bring.

However, in spite of positive experiences with colleagues and employees who had earned their teaching licenses through alternate route programs, several principals expressed concerns about alternate route teachers' level of preparation and ability to excel in the classroom. Said principal A, "I'm real concerned with alternate route people that go into tested areas." This principal and others raised concerns about alternatively certified teachers' ability to enter a classroom as a successful teacher. In particular, principals raised concerns about alternatively certified teachers' lack of field experiences and exposure to classroom practice and the impact that might have on their immediate ability to manage classrooms, in particular, to manage classrooms in middle schools.

Half of the principals expressed concerns about alternate route teachers' preparation for effective classroom management. Principal B put it this way: "Having the content knowledge is such a small part of what it takes to be a teacher ... it's about classroom management skills." Principal I told us, "I think what the alternate route people really need to focus on is classroom management."

While principal $\mathrm{J}$ recognized that most teachers learn about interacting with students and managing the classroom "on the fly" during the first years of teaching, many of the principals in our study worried that interaction and management skills could not be learned on the job, or required experience in classrooms with successful teachers. Principal H told us, "I think that's something that's going to require time in a classroom, watching maybe a good teacher do it, and I think a lot of it too is just an innate ability to deal with people- to handle kids." In our state, alternate route teachers may have little or no opportunity to observe or co-teach in another teachers' classroom before being hired as teacher of record. Two principals wondered if opportunities to observe and engage in field experiences might strengthen alternate route teachers' abilities in the classroom. For example, principal C said, "I think that ... student teaching aspect would be beneficial that first year." This principal went on to say, "I've always felt that people in even regular education route need to spend more time in the classroom before they student teach . . . more time . . observing ... more hands-on." Several principals expressed a belief in a need for pre-service experience in the classroom or observation hours for the alternatively certified teachers.

On the other hand, two other principals were less adamant about the importance of field experiences or even student teaching as prior experience for success in the first year teaching. Principal B told us that student teaching is not "a silver bullet" and depended a great deal on the mentor teacher saying "I don't think that's the one thing that would make a difference or not." Principal D echoed this belief, saying, "...if I can get a student teacher and they are working with someone who's really not grooming them then it's not much of a difference." These two principals told us that field experiences alone do not guarantee new teachers' proficiency in the classroom. The lack of a field experience was not as detrimental to perceptions of alternatively certified teachers for these two administrators.

\section{Perceptions about Need for Support During First Years of Teaching}

In general, new teachers benefit from having support during the first year or years of teaching. If principals believe that alternatively certified teachers are less ready for the classroom and require greater support during the first years, they may be less likely to hire teachers whose certification was earned through an alternate route. In our state, some alternatively certified teachers receive more support than others during the first year of teaching. Our state offers non-renewable initial licensure to alternate route teachers after two courses are completed, renewable licensure is offered if teachers complete a one or two-semester internship. During the internship, the new teacher serves as teacher-ofrecord in a classroom, and is provided with mentoring and feedback by a university supervisor. Because most new teachers seek out renewable licensure, they participate in the mentoring program provided by the university. We were interested in principals' beliefs about the level of mentoring and support needed by alternate route teachers.

The principals in our study agreed unanimously that the alternatively certified teachers benefit from 
additional support during the first year of teaching through mentoring or supervision. For example, principal H stated,

I think if we're going to do the alternate route, then there's got to be that support there .... They need it because if you've not been through the student teaching and practicum ... you're going to need mentoring even more than a new teacher that has been through a college of education.

In particular, principals talked about the importance of support and mentoring provided by the university supervisor or faculty member instead of a school administrator or even a colleague. University faculty, they told us, might make better mentors because building administrators and traditionally prepared colleagues might not understand the alternate route teachers' concerns as well as someone who has more knowledge about alternate route preparation. As principal A told us:

The university may be more familiar with what problems the person might encounter because they see it every day ... a normal mentor may see it from the point of another teacher or a teacher that went through the educational process. I don't think they'd have the background knowledge to maybe mentor them as well as someone that understands what they go through.

Principal I talked about how alternate route teachers might not want to reveal their concerns or questions to colleagues and administrators they work with. Principal I stated:

there's going to be several times throughout the year that they're going to need questions answered that they may not feel comfortable going to an administrator ... so, they have a peer, or someone that is like them to be able to help them through the difficult times of a first year teacher.

These and other principals talked about the value of having a mentor during the first years who is "not a part of out school district" in order to support alternate route teachers during their first year.

All of the principals felt that alternatively certified teachers benefit from having the support of a mentor or university supervisor during the first year, but not all principals were certain that existing mentoring programs through the state-mandated internship were enough. Principals raised concerns about the current level of support provided by some programs. Principal A spoke about programs that only visit new teachers "two times in a semester" and Principal F told us that alternatively certified teachers require "more than your traditional resources that have been available."
Principals seemed to assume that alternate route teachers would differ from that of traditional route in that traditional route participants would be accustomed to the classroom environment and district procedures because of field experiences in the preservice education program. They believed that alternatively certified teachers might need more mentoring than other new teachers, and that those mentors should be provided by someone outside of the school, such as a university faculty member.

\section{Perceptions about Incentive Programs and Required Length of Service}

The MAT-M at our institution is funded by federal grant and provides scholarships for participation in the alternate route program given teachers are employed by a partner district for at least four years after earning licensure. We wondered whether principals' views of incentive programs might impact their assumptions about alternatively certified teachers. The principals we spoke with mostly saw benefits of incentives, citing them as beneficial to schools and districts working to identify strong teachers for the classroom and a legitimate path to the profession for individuals who did not major in teacher education as undergraduates. In fact, eight participants saw value in incentive programs for recruiting teachers for schools with shortages. Principal E responded, 'I think that's real important and also helps those areas that have problems with securing good teachers. It's a win for both situations." Principal J recognized the impact would be particularly beneficial for rural areas, stating "I think it encourages people to stay local and not go outside the state." In particular, Principal I talked about how service commitments can help to address teacher retention issues for teachers who may struggle during the first year. Principal I suggested that some teachers

need those programs to help them get through the first year instead of just giving up. If they know that some of their loan forgiveness or whatever's tied to them coming back, they may give it a try for a second year, where normally they may not.

For the most part, principals spoke positively about incentive programs as tools for addressing shortages and encouraging and supporting teachers to enter the profession, however, four of the principals also noted concerns with the incentives. Principal B told us that "I don't think you produce quality folks with just monetary incentives alone, or scholarships." In particular, Principal B expressed concerns about incentives that require particular length-of-service in classrooms, such as ours: "I would not want someone 
teaching one of my children or grandchildren who was there just because they were satisfying an agreement for a scholarship." Principal J echoed concerns about incentives paired with service commitments that could be detrimental to both the school and the individual teacher, saying, "The only drawback I could see of that would be if a teacher was not a good fit-- I feel like a person would feel obligated to stay, or they would be obligated to stay because of scholarship money." Principals also worried that the requirement to serve in a particular district in exchange for a scholarship might not lead to long-term commitments that truly address teacher shortages. Principal F, for example, referred to alternatively certified teachers who taught the number of years required, but "... once that obligation time period was exhausted, they have moved on and taken that period of experience with them to a different district ... or state." The hiring district did not get the benefit of the teachers' growing expertise at the end of the required commitment. Principal D raised concerns about the impact on the new hire, particularly when the commitment requires the alternatively certified teacher to teach in a particular school or district that might not be a high achieving school. This principal told us:

if you know that you have the potential to be a good teacher, it's kind of frustrating to be in an environment where everyone else doesn't have the same goals as you. Then when you know that if you weren't obligated to this district, you'd have the potential to work elsewhere and be a bit more successful.

Principals we interviewed understood the value of incentive programs to recruit teachers for schools with teacher shortages, and believed that recruitment incentives can help schools beleaguered by shortages and provide access to the profession to strong teachers who might not otherwise become teachers. However, some worried about the long-term impact of these incentive programs. They worried that teachers recruited on the basis of scholarships and other incentives might not make strong colleagues or teachers, might not be committed to the improving their practice, and might not stay in the district past the length of the service commitment.

\section{Conclusion}

Overall, principals' general impressions of alternate route programs were positive, though they had had relatively little actual experience with alternatively certified teachers as employees or colleagues. Some positive aspects principals noted were that alternate route programs can help meet the high need for teachers in the state, and alternate route candidates might possess advantages over traditionally certified peers, including greater content knowledge, experience, and maturity. However, recurring themes across questions and subjects included concerns about the absence of student teaching, the characteristics of individuals seeking alternate route licensure including their social skills, about readiness for the classroom, and a sense that beginning alternate route teachers will need support and mentoring in the first year of teaching. These themes were presented in more than three questions and across subjects.

This study provides only a narrow look at principals' perceptions of alternate route programsten principals from rural schools in districts relatively close to our university. However, these ten principals' perceptions point to some of the strengths and some of the concerns about alternate route programs. We sought to talk to principals in order to understand their views and concerns, both to inform outreach to districts and our own job-placement efforts, and to understand the perspectives of rural administrators in order to design the degree program as a whole.

The MAT-M program at our institution was specifically developed to help meet the staffing needs of rural middle schools. Knowing that principals have concerns about mentoring first year teachers, we have worked to establish online communities that connect new teachers to their colleagues in other schools and to university staff to provide mentoring through the first three years of teaching. Understanding that principals have concerns about the characteristics of alternatively certified teachers, we have worked to develop relationships with principals in schools that may employ our graduates so that they can understand our entrance requirements and recruiting practices, and also so that principals can identify strong candidates who have connections to the school and community (e.g., teacher assistants and parent volunteers) and encourage them to use the MAT-M to become certified to teach.

These rural principals expressed concerns about recruiting and valued high standards for admissions requirements for potential alternate route teachers. As a graduate program in the College of Education at our university, admissions requirements for our program are higher than those established by the state, and making this case to those making hiring decisions helps us to place our students. We have designed our program to include mentoring through the first year of teaching with required internship coursework. Helping principals understand the design of our program and supports provided may assuage any concerns about the lack of prior field experience and lack of available mentors in small rural schools. 


\section{References}

Association for Middle Level Education (AMLE). (2012). AMLE Standards. Westerville, $\mathrm{OH}$ : Author. Retrieved from http://www.amle.org/AboutAMLE/ProfessionalP reparation/AMLEStandards.aspx

Boyd, D., Goldhaber, D., Lankford, H., \& Wyckof, J. (2007). The effect of certification and preparation on teacher quality. The Future of Children, 17(1), 45-68.

Constantine, J., Player D., Silva, T., Hallgren, K., Grider, M., \& Deke, J. (2009). An evaluation of teachers trained through different routes to certification, final report (NCEE 2009-4043). Washington, DC: National Center for Education Evaluation and Regional Assistance, Institute of Education Sciences, U.S. Department of Education.

Feistritzer, C. E., \& Haar, C. K. (2008). Alternate routes to teaching. Upper Saddle River, NJ: Pearson.

Finn, V. L. (2009). Alternatively-trained versus traditionally-trained teachers: The principals' perspective. Doctoral dissertation, University of Texas at Dallas, TX. Retrieved from http://search.proquest.com/docview/305065356

Goldhaber, D. D., \& Brewer, D. J. (2000). Does teacher certification matter? High school teacher certification status and student achievement. Educational Evaluation and Policy Analysis, 22(2). 129-145.

Grossman, P. \& Loeb, S. (2008). Alternative routes to teaching. Cambridge, MA: Harvard Education Press.

Hall, V. L. (2008). The effectiveness of the nontraditional teacher certification training program in Arkansas based on interviews by supervising principals and non-traditional teachers from the 2006--2008 cohort. Doctoral Dissertation, University of Arkansas. Retrieved from http://search.proquest.com/docview/304687985

Huss, J. (2007). Perceptions of secondary principals toward online teacher preparation. Journal of Ethnographic and Qualitative Research, 2(1), 23-31.
Ing, M., \& Loeb, S. (2008). Assessing the effectiveness of teachers from different pathways: Issues and results. In P. Grossman \& S. Loeb (Eds.), Alternative routes to teaching: Mapping the new landscape of teacher education (pp.157-186). Cambridge, MA: Harvard Education Press.

Johnson, J., Showalter, D., Klein, R., \& Lester, C. (2014). Why rural matters 2013-2014: The condition of rural education in the 50 states. Washington, D.C.: The Rural School and Community Trust.

Johnson, P. J. (2010). Principals' perceptions of the alternative certification of teacher candidates in a southeastern suburban school system as measured by their attitudes and hiring practices. Doctoral dissertation, University of West Georgia, Carrolton, GA.. Retrieved from http://search.proquest.com/docview/854513187

Mississippi Department of Education. (2015). Critical shortage areas by county. Jackson, MS. Retrieved from http://www.mde.k12.ms.us/OTC/CSA/criticalshortage-areas-by-county

Monk, D. H. (2007). Recruiting and retaining highquality teachers in rural areas. The Future of Children, 17(1), 155-174. doi: 10.1353/foc. 2007.0009

National Association for Alternative Certification (NAAC), (2012). Quality indicators for nontraditional teacher preparation programs. Washington, DC: Author. Retrieved from http://www.altteachercert.org/quality_indicators.asp

Pennefather, J. (2008). "Rural" schools and universities: The use of partnerships as a teaching strategy in enhancing a positive response to rurality. Perspectives in Education, 26(2), 81-94.

Schafft, K. A., \& Jackson, A. Y. (Eds.). (2010). Rural education for the twenty-first century: Identity, place and community in a globalizing world. University Park, PA: The Pennsylvania State University Press.

Wagmeister, J. F. (2006). A comparison of graduates' and principals' perceptions of California 
teachers prepared through alternate and

traditional certification. Doctoral dissertation,

California Lutheran University, Thousand Oaks,

CA. Retrieved from

http://search.proquest.com/docview/304914221.

Wang, A. B. (2014). The forgotten struggles of rural schools: Simply finding enough teachers can be tough. Education Week, 34(12), 24-28.

Zeichner, K. \& Hutchinson, E. A. (2000). The development of alternative certification policies and programs in the United States. In P. Grossman \& S. Loeb (Eds.), Alternative routes to teaching: Mapping the new landscape of teacher education (pp.15-29). Cambridge, MA: Harvard Education Press.

About the Authors:

Devon Brenner is Professor and Department Head of Curriculum, Instruction and Special Education at Mississippi State University.

Anastasia Elder is Associate Professor in Department of Counseling and Educational Psychology at Mississippi State University.

Sarah Wimbish is a School Psychologist Intern in Tishomingo County School District

Sara Walker is a graduate student in Educational Psychology at Mississippi State University.

Authors wish to acknowledge work of Matthew Alred in accomplishing this research. 